\title{
Holmium-166 Microspheres are Visible in Target Liver Lesions on Unenhanced Computed Tomography
}

\author{
Lawrence Bonne $^{1,2}$, Pieter De Bondt ${ }^{3}$, Filip Sermon ${ }^{4}$, Geert Maleux $^{2}$
}

1) Department of Radiology, OLV Hospital Aalst, Aalst; 2) Department of Radiology, University Hospitals Leuven, Leuven; 3) Department of Nuclear Medicine, OLV Hospital Aalst, Aalst; 4) Department of Gastroenterology, OLV Hospital Aalst, Aalst, Belgium
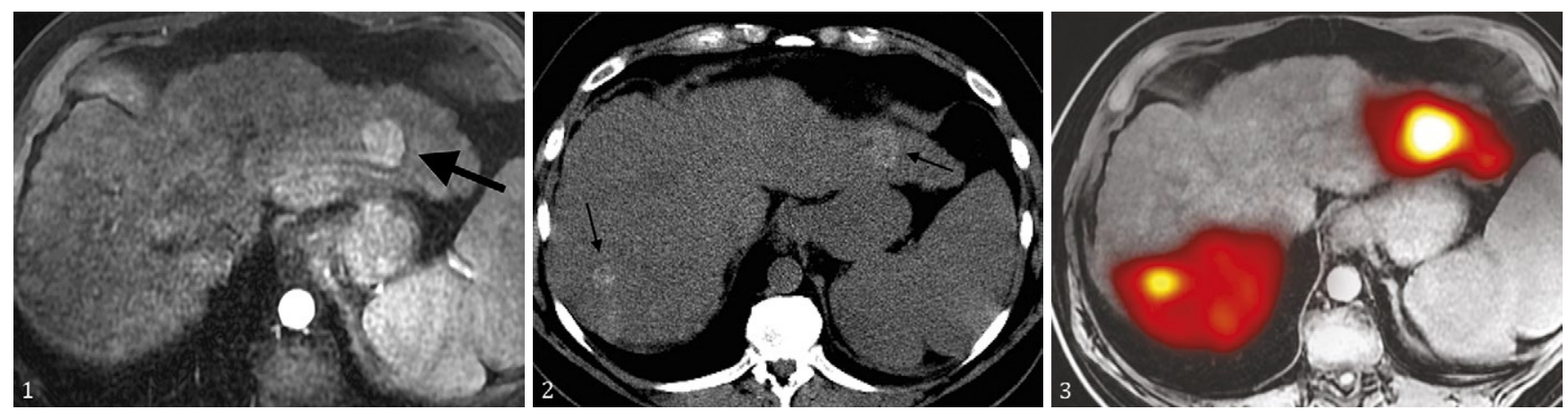

A 70-year-old woman presented with alcohol-induced liver cirrhosis associated with two hypervascular hepatocellular carcinoma (HCC) liver lesions in segment 3 and 7 with a diameter of $28 \mathrm{~mm}$ and $15 \mathrm{~mm}$ respectively based on contrastenhanced magnetic resonance imaging. (Fig. 1: early-phase, segment 3 of the left liver lobe, black arrow). The patient was deemed not eligible for ablative therapy and catheter-directed superselective radioembolization of both tumoral segments using Holmium-166 microspheres (Quirem-Terumo, Utrecht, the Netherlands) was performed [1-3].

Unenhanced computed tomography (CT) 4 days after Holmium-166-radioembolization revealed a spontaneously hyperdense aspect of both lesions (Fig. 2, black arrows), corresponding to areas of gamma radiation on post-treatment SPECT (single photon emission computed tomography)-CT fusion imaging (Fig. 3) [4]. Treatment radiation doses were estimated at 344 Gray (Gy) for the lesion in segment 3 and $211 \mathrm{~Gy}$ for the lesion in segment 7.

The spontaneously hyperdense appearance of both HCClesions on unenhanced CT is most probably related to a high intratumoral concentration of Holmium-166 microspheres. Due to the high atomic number, Holmium-166 has a high $\mathrm{X}$-ray attenuation coefficient, much higher than Iodine-129 and Yttrium-90 molecules. This characteristic makes Holmium-166 microspheres, if present in sufficiently high concentrations as seen in radiation segmentectomy cases with superselective dose administration, detectable on unenhanced, post-treatment CT imaging. This CT-observation previously was also found in a porcine model used for in vivo experimental evaluation of safety and feasibility of Holmium-166 radioembolization [5].

Corresponding author: Geert Maleux, geert.maleux@uzleuven.be

Conflicts of interest: None to declare.

\section{REFERENCES}

1. Sohn JH, Choi HJ, Lee JT, et al. Phase II study of Holmium-166-Chitosan complex treatment in patients with a single, large hepatocellular carcinoma. Oncology 2009;76:1-9. doi:10.1159/000173735

2. Smits ML, Nijsen JF, van den Bosch MA, et al. Holmium-166 radioembolisation in patients with unresectable, chemorefractory liver metastases (HEPAR trial): a phase 1, dose-escalation study. Lancet Oncol 2012;13:1025-1034. doi:10.1016/S1470-2045(12)70334-0

3. Radosa CG, Radosa JC, Grosche-Schlee S, et al. Holmium-166 radioembolization in hepatocellular carcinoma: Feasibility and safety of a new treatment option in clinical practice. Cardiovasc Intervent Radiol 2019;42:405-412. doi:10.1007/s00270-018-2133-7

4. Reinders MTM, Smits MLJ, van Roekel C, Braat AJAT. Holmium-166 microsphere radioembolisation of hepatic malignancies. Semin Nucl Med 2019;49:405-412. doi:10.1053/j.semnuclmed.2019.01.008

5. Vente MA, de Wit TC, van den Bosch MA, et al. Holmium-166 poly(Llactic acid) microsphere radioembolisation of the liver: technical aspects studied in a large animal model. Eur Radiol 2010;20:862-869. doi:10.1007/s00330-009-1613-1 